\title{
Research of efficiency of the organic Rankine cycle on a mathematical model
}

\author{
N. Galashov ${ }^{1, *}, S$. Tsibulskiy ${ }^{1}, A$. Gabdullina $^{1}, D$. Melnikov $^{1}$, and $A$. Kiselev ${ }^{1}$ \\ ${ }^{1}$ National Research Tomsk Polytechnic University, 634050 Tomsk, Russia
}

\begin{abstract}
The object of the study are the organic Rankine cycle. The purpose of research is to evaluate the impact on the net efficiency of the initial and final properties of the cycle at work on a saturated and superheated steam. Investigations were carried out on the basis of a mathematical model, in which the thermodynamic properties of materials are determined on the basis of "REFPROP". On the basis of the available scientific publications on the use of working fluids in an organic Rankine cycle analysis was selected ozone-safe pentane. A mathematical model has been developed on condition that condenser is used as air cooler which allows the substance to condense at a temperature below $0{ }^{\circ} \mathrm{C}$. Numerical study on the mathematical model shown that net efficiency at work on pentane linearly depends on the condensation temperature and parabolically depends on the initial temperature with the saturated steam. During work at the superheated steam efficiency strongly depends on both the initial temperature and of the initial pressure. With rising initial temperature is necessary to gradually increase the initial pressure under certain conditions.
\end{abstract}

\section{Introduction}

Organic Rankine Cycle (ORC) - is a cycle, the working fluid which is a low boiling substance (LBS). The use of the working substance LBS allows you to solve a number of problems that are available at the water as the working body: to reduce the temperature of heat removal by the use of air cooled condensers in the winter and by this increase the efficiency of the cycle; due to the high density to reduce the size, weight and cost of facilities; by condensing steam at high pressures to reduce or solve air inflow in the condenser and improve condenser heat exchange therein. Application of air cooled condensers in the ORC can also eliminate or significantly reduce the consumption of water for technological purposes, it is very urgent task both in industry and in the energy sector. Therefore, in recent years in the scientific literature appeared a large number of studies devoted to the use ORC [1-9]. Basically, ORC is used to generate electricity through the use of low-grade waste heat, but as shown in [10] it can be used in a combined cycle gas turbine (CCGT) and diagram of powerful generating thermal and nuclear power plants.

\footnotetext{
*Corresponding author: gal@tpu.ru
} 
Economic, environmental and safety measure of ORC are strongly dependent on the type of LBS. Environmentally friendly LBS determined ozone depletion potential ODP and global warming potential GWP.

\section{Subject of research}

The object of study is power installation with air cooled condenser, working on the basis of the Organic Rankine cycle, diagram is shown in Figure 1.

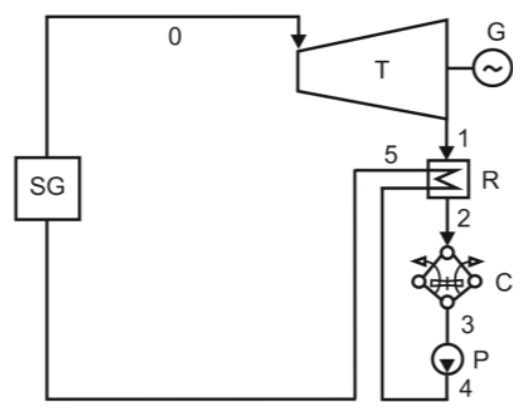

Fig. 1. Diagram installation: SG - a steam generator; $T$ - turbine; $G$ - generator; R - regenerator; $C$ condenser; P - pump; 0 - condition steam before the turbine; 1 - the output of the turbine; 2 - for the regenerator; 3 - liquid condition of the condenser; 4 - downstream of the pump; 5 - for the regenerator.

Consider the principle of installation work shown in Figure 1. In the steam generator is carried out heating, evaporation and possible overheating of the LBS. Then the LBS steam with properties at 0 enters turbine $T$ where does work and set in motion generator. At the outlet of steam turbine at 1 depending on the properties the LBS is adjudged to wet or superheated steam. If steam is superheated state, that in the regenerator it is cooled to state 2 , which is $1-5^{\circ} \mathrm{C}$ above the saturation temperature at the pressure in the condenser. In the condenser steam condenses and condensate in the state 3 is pumped through the regenerator to the steam generator. In this case the condensate is heated in the pump due to compression work, and in a regenerator by cooling steam. Condensate properties of downstream from the pump characterize the state 4 , and state of the regenerator 5 .

Application air-cooled condenser allows the condensed LBS steam at a temperature below $0{ }^{\circ} \mathrm{C}$, it conditions is impossible to have a water-cooled condenser.

\section{Mathematical model calculation installation of the ORC}

The mathematical model for calculating the properties and efficiency ORC with air cooled condenser is designed on the basis of Figure 1.

The initial data are given:

- the working fluid;

- temperature $t_{0}$ and pressure $P_{0}$ at the turbine inlet;

- the temperature in the condenser $t_{\mathrm{C}}$;

- step-up ratio of the pressure in the pump $k_{\mathrm{P}}$;

- step-up ratio of pressure increase in the regenerator $k_{R}$;

- steam superheating at the outlet from the regenerator $\Delta t_{\mathrm{R}}$;

- efficiency of the regenerator $\eta_{R}$;

- efficiency of the pump $\eta_{\mathrm{P}}$; 
- net efficiency of the turbine during operation with superheated steam $\eta_{o i s s}$.

Calculation algorithm

If only given temperature $t_{0}$, the steam pressure is saturated and equals:

$$
P_{0}=\mathrm{f}\left(t_{0}\right) \text {. }
$$

Enthalpy and entropy:

$$
h_{0}=\mathrm{f}\left(t_{0}\right), \mathrm{s}_{0}=\mathrm{f}\left(t_{0}\right) .
$$

During operation on the ORC superheated steam initial parameters of the working substance:

$$
h_{0}=\mathrm{f}\left(t_{0}, P_{0}\right), s_{0}=\mathrm{f}\left(t_{0}, P_{0}\right) .
$$

Steam pressure in the condenser:

$$
P_{\mathrm{C}}=\mathrm{f}\left(t_{\mathrm{C}}\right) \text {. }
$$

Steam pressure at the outlet from the turbine in view of the pressure loss in the regenerator:

$$
P_{1}=k_{\mathrm{R}} P_{\mathrm{C}}
$$

Steam enthalpy at the turbine outlet at isentropic process:

$$
h_{1 \mathrm{t}}=\mathrm{f}\left(P_{1}, S_{0}\right) \text {. }
$$

Work $1 \mathrm{~kg}$ of steam in the turbine at isentropic process:

$$
H_{0}=h_{0}-h_{1 \mathrm{t}}
$$

The enthalpies of liquid and steam in the saturated state at the pressure $P_{1}$ :

$$
h_{1}{ }^{\prime}=\mathrm{f}\left(P_{1}\right), h_{1}{ }^{\prime}=\mathrm{f}\left(P_{1}\right)
$$

The degree of dryness of the steam at the end of the isentropic process in the turbine:

$$
x_{1}=\left(h_{1 \mathrm{t}}-h_{1}{ }^{\prime}\right) /\left(h_{1}{ }^{\prime \prime}-h_{1}{ }^{\prime}\right)
$$

Coefficient of energy loss from moisture in the turbine:

$$
\text { if } x_{1}>1 \text {, then } k_{\mathrm{ms}}=1 \text {, another } k_{\mathrm{ms}}=\left[1-0.8(1-0.15)\left(1-x_{1}\right) / 2\left(H_{\mathrm{ms}} / H_{0}\right)\right]
$$

Turbine internal efficiency with account for the loss of energy from the humidity:

$$
\eta_{o i}=k_{\mathrm{ms}} \eta_{o i . \mathrm{Ss}}
$$

The enthalpy of steam at the turbine outlet considering energy loss:

$$
h_{1}=h_{0}-\eta_{o i} H_{0} .
$$

Work done by $1 \mathrm{~kg}$ steam in the turbine process with account for the loss of energy:

$$
H_{i}=h_{0}-h_{1} \text {. }
$$

Steam temperature at the turbine outlet: 


$$
t_{1}=\mathrm{f}\left(P_{1}, h_{1}\right)
$$

If $t_{1}-t_{\mathrm{C}}<5$, then $\Delta t_{\mathrm{R}}=0$.

Temperature and enthalpy of steam at the outlet of the regenerator:

$$
t_{2}=t_{\mathrm{C}}+\Delta t_{\mathrm{R}}, h_{2}=\mathrm{f}\left(P_{\mathrm{C}}, t_{\mathrm{R}}\right) .
$$

The change of the steam enthalpy in the regenerator:

$$
\Delta h_{\mathrm{R}}=h_{1}-h_{2} .
$$

The enthalpy and the entropy of the liquid at the outlet of the condenser:

$$
h_{3}{ }^{\prime}=\mathrm{f}\left(P_{\mathrm{C}}\right), S_{3}{ }^{\prime}=\mathrm{f}\left(P_{\mathrm{C}}\right) .
$$

The pressure of the pump:

$$
P_{4}=k_{\mathrm{P}} P_{0} .
$$

The enthalpy of the pump in the isentropic compression process:

$$
h_{4}=\mathrm{f}\left(P_{4}, S_{3}{ }^{\prime}\right) .
$$

Increasing entropy in the pump:

$$
\Delta h_{\mathrm{P}}=\left(h_{4}-h_{3}{ }^{\prime}\right) / \eta_{\mathrm{P}}
$$

The enthalpy of liquid in the regenerator:

$$
h_{5}=h_{3}{ }^{\prime}+\Delta h_{\mathrm{P}}+\eta_{\mathrm{R}} \Delta h_{\mathrm{R}}
$$

Net cycle efficiency, \%:

$$
\eta_{i}=100\left[\left(h_{0}-h_{1}\right)-\Delta h_{\mathrm{P}}\right] /\left(h_{0}-h_{5}\right) .
$$

The model is implemented mathematical program in the package Excel spreadsheets. The calculations of properties of all substances produced based on the functions of the database "REFPROP" [11, 12].

\section{Experimental results and analysis}

Investigations were carried out with the following initial data:

- the working fluid - pentane;

- temperature $t_{0}$ and pressure $P_{0}$ at the turbine inlet;

- condenser temperature $t_{\mathrm{C}}=-20-50{ }^{\circ} \mathrm{C}$;

- coefficient of pressure increase in the pump $k_{\mathrm{P}}=1.15$;

- coefficient of pressure increase in the regenerator $k_{\mathrm{R}}=1.1$;

- superheat at the outlet of the regenerator $\Delta t_{\mathrm{R}}=3^{\circ} \mathrm{C}$;

- the efficiency of the regenerator $\eta_{\mathrm{R}}=0.98$;

- pump efficiency $\eta_{P}=0.7$

- net efficiency of the turbine during operation with superheated steam $\eta_{o i s s}=0.87$;

Pentane is selected for investigation as one of the substances, the most recommended in scientific works for use in the ORC. 
Numerical studies have been conducted with operation for saturated steam from condensing temperature change from -20 to $50{ }^{\circ} \mathrm{C}$ and the initial temperature of 100 to $180^{\circ} \mathrm{C}$.

Fig. 2 shows the resulting the efficiency investigations.

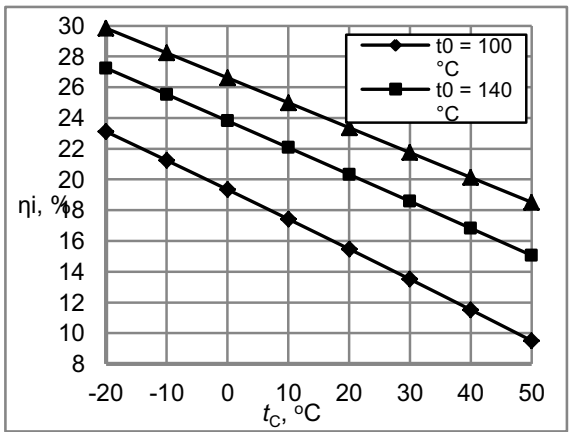

a

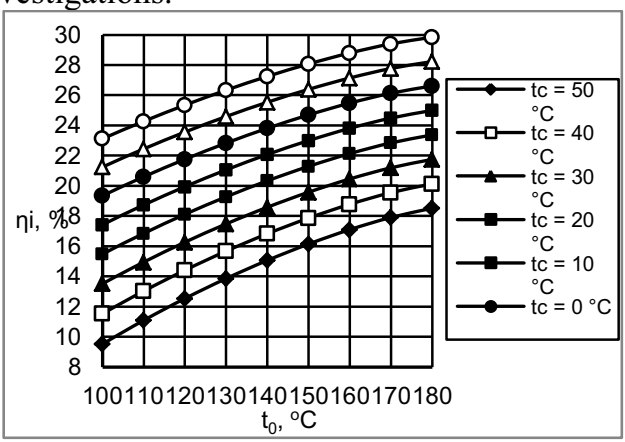

b

Fig. 2. $a$-dependence of the net efficiency ORC from $t_{\mathrm{C}}$ and $t_{0}, b$-dependence of the net efficiency $\mathrm{ORC}$ from $t_{0}$ and $t_{\mathrm{C}}$.

In fig. $2 a$ can see that the efficiency has a linear function from $t_{\mathrm{C}}$ and nonlinear from $t_{0}$. With a decrease $t_{\mathrm{C}}$ on $10^{\circ} \mathrm{C}$ efficiency increased by $0.8-1 \%$. In fig. $2 b$ net efficiency takes the form of a parabolic dependence. By increasing $t_{0}$ the efficiency growth slows.

Fig. 3 shows results of investigations operation with superheated steam at a initial properties $t_{0}, P_{0}$ and the temperature in condenser $10{ }^{\circ} \mathrm{C}$.

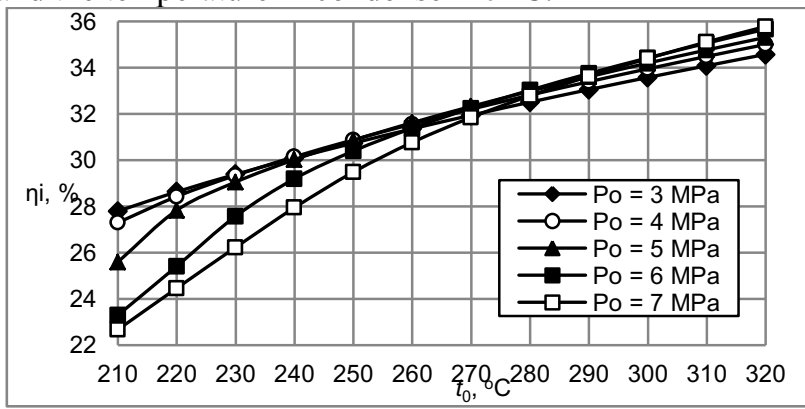

Fig. 3. Dependence of the net efficiency ORC from $t_{0}$ and $P_{0}$ with conditions $t_{\mathrm{C}}=10^{\circ} \mathrm{C}$.

Fig. 3 shows that the net efficiency strongly depends on $t_{0}$ and $P_{0}$. At the same time, up to $t_{0}<240{ }^{\circ} \mathrm{C}$ profitably operate at $P_{0}=3 \mathrm{MPa}$, for $t_{0}=240-270{ }^{\circ} \mathrm{C}$ to operate at profitable $P_{0}=4 \mathrm{MPa}$, and at $t_{0}>290{ }^{\circ} \mathrm{C}$ profitably operate at $P_{0}=7 \mathrm{MPa}$.

\section{Conclusion}

At operate on saturated steam net efficiency of the cycle at work on pentane linearly depends on the condensation temperature and parabolically depends on the initial temperature.

Efficiency strongly depends on both the initial temperature and the initial pressure at work with superheated steam. With increasing initial temperature need to gradually increase the initial pressure under certain conditions. 
The research was realized with financial support of Minobrnauki of Russia in framework of FTP "Research and development in prior direction of scientific-technological complex of Russia in 2014-2020 years”, unique R\&D identifier RFMEFI58114X0001.

\section{References}

1. M. Soffiato, C.A. Frangopoulos, G. Manente, S. Rech, A. Lazzaretto, Energy Convers. Manage 92, 12 (2015)

2. B.C. Choi, Y.M. Kim, Energy 58, 404 (2013)

3. U. Larsen, L. Pierobon, F. Haglind, C. Gabrieli, Energy 55, 803 (2013)

4. G. Shu, L. Liu, H. Tian, H. Wei, G. Yu, Appl. Energ. 113, 1188 (2014)

5. A. Toffolo, A. Lazzaretto, G. Manente, M. Paci, Appl. Energ. 121, 219 (2014)

6. M. Yang, R. Yeh, Energy Convers Manage 88, 12 (2014)

7. T. Guo, H.X. Wang, S.J. Zhang, Energy 36, 2639 (2011)

8. A. Lazzaretto, G. Manente, Int. J. Thermodyn. 17, 3 (2014)

9. L. Branchini, A. De Pascale, A. Peretto, Appl. Therm. Eng. 61, 129 (2013)

10. N. Galashov, S. Tsybulsky, Power Techn. Eng. 48, 5 (2015)

11. E. Lemmon, M. Huber, M. McLinden, Reference fluid thermodynamic and transport properties-REFPROP, standard reference database 23, version 8.0, National Institute of Standard and Technology (2007)

12. N. Galashov, S. Tsibulskiy, T. Serova, EPJ Web Conf. 110, 01068 (2016) 